DOI: 10.4274/jarem.galenos.2020.3703

J Acad Res Med 2020;10(3):306-8

\title{
Anesthetic Approach for a Patient with 1q21.1 Microdeletion Syndrome: A Case Report
}

\author{
(1) Gül Cansever, (1) Cansu Uzuntürk, (1) Nur Canbolat
}

İstanbul University, İstanbul Faculty of Medicine, Department of Anesthesiology and Reanimation, İstanbul, Turkey

Cite this article as: Cansever G, Uzuntürk C, Canbolat N. Anesthetic Approach for a Patient with 1q21.1 Microdeletion Syndrome: A Case Report. J Acad Res Med 2020;10(3):306-8

\begin{abstract}
1 q21.1 microdeletion syndrome is a chromosome abnormality where segment of genetic material on the long (q) arm of chromosome 1 at position 21.1 is missing or deleted. Distal 1q21.1 microdeletion is associated with microcephaly, macrocephaly, mental retardation, craniofacial dysmorphism, cardiac abnormalities, and cataracts, while proximal 1q21.1 microdeletion is associated with thrombocytopenia-absent radius syndrome and skeletal, cardiac, and genitourinary system abnormalities. Moreover, patients with 1q21.1 microdeletion syndrome have no unique facial features; however, $75 \%$ of the carriers have craniofacial dysmorphism. Short stature (50\%), microcephaly (22\%), cleft palate, cleft lip, long philtrum, frontal bossing, epicanthal folds, and bulbous nose can be seen among these patients. Although there is delay in motor development in $50 \%-75 \%$ of these patients, mental retardation is typically mild to moderate. Neurological symptoms such as tremor (44\%), hyperreflexia (35\%), and hypotonia (35\%) have been reported in the literature. In addition, seizure occurs at a frequency of $10 \%-20 \%$ and starts at an early age. Psychiatric conditions such as autism spectrum, attention-deficit hyperactivity, and mood and anxiety disorders might also occasionally accompany 1 q21.1 microdeletion syndrome. In this case report, we discuss our anesthetic experience with a 3-year-old boy diagnosed with this syndrome, for whom an orthopedic clinic planned a posterior spinal instrumentation. Further, this is the first case in the literature on anesthetic treatment of patient with $1 \mathrm{q} 21.1$ microdeletion syndrome.
\end{abstract}

Keywords: 1q21.1 microdeletion syndrome, difficult intubation, general anesthesia, posterior spinal instrumentation

\section{INTRODUCTION}

$1 \mathrm{q} 21.1$ microdeletion syndrome is a rare disease. While some carriers of this microdeletion show no phenotype, some have craniofacial dysmorphism and cardiac, genitourinary, and neurological abnormalities (1-3).

\section{CASE PRESENTATION}

The orthopedic clinic planned a posterior spinal instrumentation for a 3-year-old, $12 \mathrm{~kg}$ male patient diagnosed with 1q21.1 microdeletion syndrome. Additionally, parental's informed consent was obtained.

The patient was born in the $27^{\text {th }}$ gestational week by emergency cesarean delivery due to fetal bradycardia. Moreover, he was intubated and taken to the newborn intensive care unit (ICU) due to lack of spontaneous breathing. Later on, ultrasonography revealed hemorrhage in the left periventricular region leading to a moderate communicating hydrocephalus. Echocardiography showed patent foramen ovale and mild mitral insufficiency. Later, cerebral palsy and premature retinopathy were diagnosed.

ORCID IDs of the authors: G.C. 0000-0001-9627-2294; C.U. 0000-0001-8266-8888; N.C. 0000-0003-1490-3027. 
Genetic analysis conducted during ICU hospitalization revealed 1q21.1 microdeletion in his mother and himself.

In preoperative anesthesia examination, he had scaphocephaly, long philtrum, and pointed forehead (Figure 1). Difficult airways were predicted since the patient's Mallampati score was 3. Physical examination demonstrated weakness in the right arm and imbalanced walking when taking the right step. Mild mitral insufficiency persisted in the latest echocardiography performed by the pediatric cardiologist; thus, postoperative heart rate, blood pressure, electrocardiography, and electrolyte follow-up were recommended.

Various sizes of face masks, endotracheal tube (ETT), Miller and Macintosh blade, stylet, and laryngeal mask airway were prepared for intubation. Moreover, peripheral oxygen saturation, electrocardiography, non-invasive blood pressure, and core temperature monitoring were installed. Anesthesia induction was also performed with $8 \%$ sevoflurane. The mask ventilation with airway was done by two anesthetists. Further, the patient received fentanyl $1 \mathrm{mcg} / \mathrm{kg}$ and rocuronium $0.6 \mathrm{mg} / \mathrm{kg}$ intravenously. He had a Cormack-Lehane score of 1 and was easily intubated with a 4.0-cuffed ETT on Macintosh 1 blade. Volume-controlled ventilation began with a positive end-expiratory pressure of 4 $\mathrm{cm} \mathrm{H}_{2} \mathrm{O}$ and median peak pressure of $19 \mathrm{~cm} \mathrm{H}_{2} \mathrm{O}$, enabling tidal volume of 6-8 $\mathrm{mL} / \mathrm{kg}$. Also, invasive arterial pressure monitoring was performed, and central venous catheter was then inserted. Additionally, anesthesia was preserved with oxygen/air and remifentanil and propofol infusions. The patient was then given a prone position. When the peak pressure was elevated (above 30 $\mathrm{cm} \mathrm{H}_{2} \mathrm{O}$ ) and $\mathrm{ETCO}_{2}$ was low, pressure-controlled ventilation was

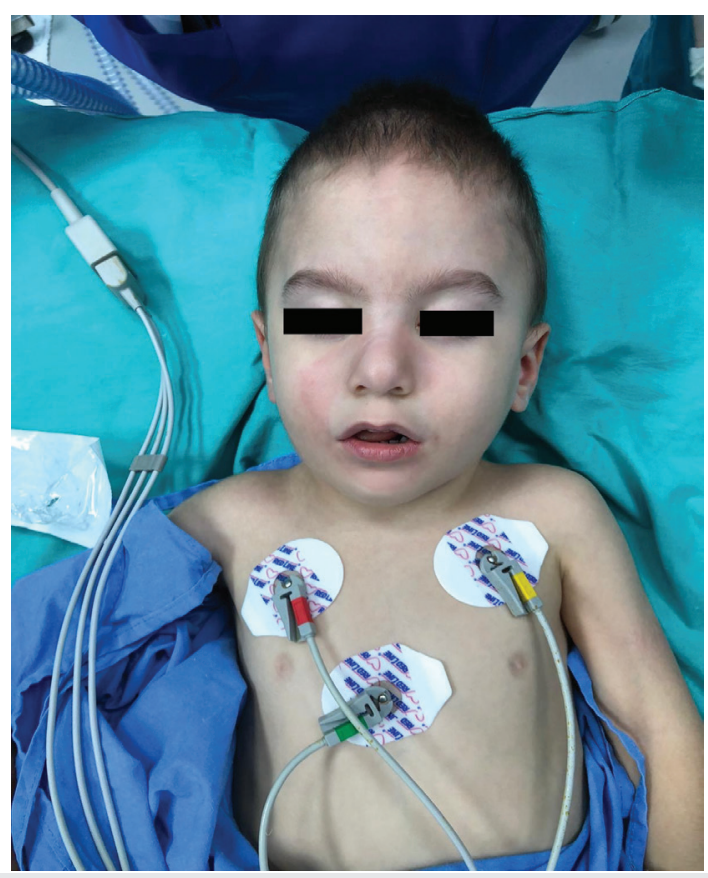

Figure 1. Frontal view and facial anomalies of the patient initiated to prevent lung damage caused by the ventilator. He was also administered with methylprednisolone $12 \mathrm{mg}$ intravenously and inhaler bronchodilators to prevent airway edema. Tidal volume was reduced to less than $6 \mathrm{~mL} / \mathrm{kg}$; thus, peak pressure returned to normal $\left(16 \mathrm{~cm} \mathrm{H}_{2} \mathrm{O}\right.$ ). Somatosensory and motor evoked potentials were also monitored. The estimated blood loss $(130 \mathrm{~mL}$ ) was supplemented by $750 \mathrm{~mL}$ of crystalloid solution, and the urine output was $33 \mathrm{cc}$. The surgery lasted for 200 minutes. Moreover, postoperative analgesia was achieved with $15 \mathrm{mg} / \mathrm{kg}$ paracetamol and $1 \mathrm{mg} / \mathrm{kg}$ tramadol. The supine position was then restored, and after extubation, he was transported to the ICU. Erythrocyte suspensions of $25 \mathrm{~mL} / \mathrm{kg}(\sim 300 \mathrm{~mL})$ and fresh frozen plasmas of $15 \mathrm{~mL} / \mathrm{kg}$ were also administered. After 5 days, he was discharged.

\section{DISCUSSION}

1q21.1 microdeletion syndrome is clinically characterized by variable phenotypes. Craniofacial dysmorphism is one of the causes of difficult airways (4). If suspected, difficult intubation equipment and ancillary health personnel should be present in the operating room.

Cardiac evaluation of the patient is important in terms of mitral valve and congenital heart diseases and atrial fibrillation $(1,5)$. Our patient's patent foramen ovale closed with medical treatment and mild mitral insufficiency persisted.

Increased secretion caused by crying and his prone position contributed to an increase in peak pressure. Barotrauma was avoided through aspiration, switching to pressure-controlled ventilation and targeting the lowest peak pressure.

Special attention should be paid to thrombocytopenia when dealing with 1q21.1 microdeletion (3).

Neurology consultation should be needed. The potential interaction of the patient's own medications and the drugs used in anesthesia is significant in reducing perioperative morbidity and mortality. His physical examination revealed loss of strength in his right arm and an imbalance due to cerebral palsy.

\section{CONCLUSION}

1q21.1 microdeletion is a rare syndrome concerning many systems and should be further studied. This syndrome requires a thorough preoperative anesthesia examination and preparation for possible complications in the operating room. Since this condition is associated with craniofacial dysmorphisms, difficult airways should be considered. Although respiratory distress was not an established characteristic of 1q21.1 microdeletion, it was experienced in our case. Furthermore, we treated bronchospasm with inhaler bronchodilators, intravenous steroids, and ventilatorinduced lung injury prevention strategies such as low tidal volume and peak pressure.

Informed Consent: Parental's informed consent was obtained.

Peer-review: Externally and internally peer-reviewed. 
Author Contributions: Surgical and Medical Practices - G.C.; Concept G.C.; Design - G.C.; Data Collection or Processing - G.C.; Analysis and/ or Interpretation - N.C.; Literature Search - C.U., N.C.; Writing Manuscript - C.U., N.C.

Conflict of Interest: The authors have no conflict of interest to declare.

Financial Disclosure: The authors declared that this study has received no financial support.

\section{REFERENCES}

1. Bernier R, Steinman KJ, Reilly B, Wallace AS, Sherr EH, Pojman N, et al. Clinical phenotype of the recurrent 1q21.1 copy-number variant. Genet Med 2016; 18: 341-9.
2. Mefford HC, Sharp AJ, Baker C, Itsara A, Jiang Z, Buysse $K$, et al. Recurrent rearrangements of chromosome 1q21.1 and variable pediatric phenotypes. N Engl J Med 2008; 359: 1685-99.

3. Brunetti-Pierri N, Berg JS, Scaglia F, Belmont J, Bacino CA, Sahoo T, et al. Recurrent reciprocal 1q21.1 deletions and duplications associated with microcephaly or macrocephaly and developmental and behavioral abnormalities. Nat Genet 2008; 40: 1466-71.

4. Peterson GN, Domino KB, Caplan RA, Posner KL, Lee LA, Cheney FW. Management of the difficult airway: A Closed Claims Analysis. Anesthesiology 2005; 103: 33-9.

5. Christiansen J, Dyck JD, Elyas BG, Lilley M, Bamforth JS, Hicks M, et al. Chromosome 1q21.1 contiguous gene deletion is associated with congenital heart disease. CircRes 2004; 94: 1429-35. 